\title{
Deterioration of Pulmonary Functions in Type 2 Diabetes Mellitus
}

\author{
Shravya Keerthi $\mathrm{G}^{1}$, Sharan B Singh $\mathrm{M}^{1}$, Hari Krishna Bandi ${ }^{2}$, Suresh $\mathrm{M}^{3}$, \\ Preetham J K ${ }^{4}$, Mallikarjuna Reddy $\mathrm{N}^{1}$ \\ ${ }^{I}$ Dept. of Physiology, Narayana Medical College (NMC), Nellore, Andhra Pradesh, India. \\ ${ }^{2}$ Dept. of Physiology, Jawaharlal Institute of Postgraduate Medical Education and Research (JIPMER), \\ Puducherry, India. \\ ${ }^{3}$ Dept. of Physiology, Meenakshi Medical College and Research Institute (MMCH\&RI), Kanchipuram, India. \\ ${ }^{4}$ Dept. of Physiology, All India Institute of Medical Sciences (AIIMS), New Delhi, India.
}

\begin{abstract}
Background: Diabetes mellitus is a leading public health problem with increasing incidence and long term complications such as diabetic nephropathy, diabetic neuropathy, diabetic retinopathy etc. These complications are mainly a consequence of macrovascular and microvascular damages of the target organs. The presence of an extensive microvascular circulation and abundant connective tissue in the lungs, raises the possibility that lung tissue may be affected by microangiopathic process and non-enzymatic glycosylation of tissue proteins, induced by chronic hyperglycemia, there by rendering the lung a "target organ" in diabetic patients.
\end{abstract}

Objectives: To study the effect of type 2 Diabetes and role of gender on pulmonary function.

Methodology: This is a cross-sectional study, the test group were Type 2 Diabetes Mellitus patients $(n=50)$, the control group were staff of Narayana medical college $(n=50)$. Written consent was obtained from them. The following pulmonary function parameters were recorded: Forced Vital Capacity (FVC), Forced Expiratory Volume in the first second $\left(\boldsymbol{F E V} V_{l}\right)$, Forced Expiratory Volume percent $\left(\boldsymbol{F E} \boldsymbol{V}_{1} / \boldsymbol{F V C} \boldsymbol{\%}\right)$, Peak Expiratory Flow Rate (PEFR), Forced Expiratory Flow 25-75\% (FEF $\left.{ }_{25-75 \%}\right)$, Maximum Voluntary Ventilation $(\mathbf{M V} \boldsymbol{V})$.

Result: The mean $F V C, F E V_{l}, F E V_{l} / F V C \%$, , PEFR, $F E F_{25-75} \%, M V V$ values are low in diabetics ( $p$ value $<0.001)$ compared to non-diabetics. Also, female diabetics show greater decrease in PFT values than male diabetics

Conclusion: We conclude that diabetics show a decrease in PFT values compared to non-diabetics. Also, female diabetics are more prone to respiratory dysfunction than male diabetics. The findings of present study suggest that, lung is a target organ for damage in diabetes and the glycemic exposure is a strong determinant of reduced pulmonary function in type 2 diabetics.

Key words: Chronic hyperglycemia, Diabetes mellitus, Microangiopathy, Micro vascular circulation, Nonenzymatic glycosylation, Pulmonary function tests.

\section{Introduction}

According to World Health Organization (WHO), the term Diabetes Mellitus (DM) describes a metabolic disorder of multiple aetiology, characterized by chronic hyperglycemia with disturbances of carbohydrate, protein and fat metabolism, resulting from defects in insulin secretion or insulin action or both[1]. Diabetes mellitus is a leading public health problem with increasing incidence and long term complications such as diabetic nephropathy, diabetic neuropathy, diabetic retinopathy etc. These complications are mainly a consequence of macrovascular and micro vascular damages of the target organs [1]. According to WHO, the prevalence of Diabetes Mellitus has reached epidemic proportions . The total number of people worldwide with diabetes is projected to rise from 150 million in 2000 to 435 million in 2030 [2]. The top three countries are India, China and U.S. India is called Diabetic Capital of World as there www.iosrjournals.org 
are going to be eighty percent of all diabetics from the entire world population, concentrated here [2]. In 2000 the number of people with diabetes was 31.7 million and it is expected that by 2030 this will increase to 79.4 millions [3]. There is one person in the world dying of diabetes every ten seconds and new diabetic cases being identified every ten seconds. The worst affected are people in the age group of 40 to 59 years [2]. Several factors contributing to this include greater longevity, obesity, unsatisfactory diet, sedentary lifestyle and increasing urbanization. The cause of clinical diabetes is absolute or relative deficiency of insulin. Type1 or IDDM is due to insulin deficiency caused by autoimmune destruction of B cells in the islets of pancreas, the A, D and F cells remain intact [4]. The second form of diabetes mellitus is Type 2 or NIDDM, is characterized by insulin resistance and impaired insulin receptors. It is common type of diabetes and usually develops after the age of 40 years. It is associated with normal B cell morphology [4]. Type 2 diabetes comprises $90 \%$ of people with diabetes all around the world, and is largely the result of excess body weight and physical inactivity [2]. The presence of an extensive micro vascular circulation and abundant connective tissue in the lungs raises the possibility that lung tissue may be affected by Microangiopathy process and non-enzymatic glycosylation of tissue proteins, induced by chronic hyperglycemia, there by rendering the lung a "target organ" in diabetic patients. Since normal lung mechanics and gas exchange are influenced by the integrity of pulmonary connective tissue and microvasculature, abnormalities in either of these two structural components of the lung may lead to the development of measurable abnormalities of pulmonary function [5]. In 2004, Wendy A. Davis et al. observed that a $10 \%$ decrease in $\mathrm{FEV}_{1}$ was associated with $12 \%$ increase in all-cause mortality [6]. This finding is consistent with Wisconsin epidemiologic study of diabetic retinopathy data showing an association between PEFR and mortality [6].

As measures of airflow limitation predict all-cause mortality in type 2 diabetes, intensive glycemic management may reduce the risk of death through improved ventilatory function independent of other beneficial effects. So, the assessment of pulmonary function is an important investigation because early detection of functional impairment and its appropriate treatment will help to reduce morbidity and mortality. Therefore, the present study was planned to assess the status of pulmonary functions in diabetics and find the gender difference in them if exists.

\section{Materials and Methods}

This is a cross-sectional study undertaken by the Department of Physiology, Pulmonary Function Testing Laboratory, Narayana medical college (NMC), Nellore (A.P), India. After obtaining approval of Institutional Ethics Committee (IEC), the test group patients $(n=50)$ type 2 diabetic patients were recruited from OPD and central laboratory of NMC and hospital. The control group subjects $(\mathrm{n}=50)$ were teaching and non-teaching staff of NMC. The subjects of both gender in the age group between 30-60 years are included. Subjects with past history of smoking, hypertension, respiratory diseases, chest wall injuries, congestive cardiac failure, and kyphoscoliosis were excluded from the study. The subjects were properly explained about the objectives, methodology, expected outcome and implications of the study and written informed consents were obtained from them. They were instructed to report to PFT lab of Physiology department at about 9 A.M.

Following 5 minutes sitting rest in the lab, their pulmonary functions were assessed by computerized spirometer (Spirowin Version 2.0 of Genesis Medical systems pvt Ltd) which gives ERS-93 predicted values at BTPS conditions [7]. At the beginning, satisfactory demonstrations were given regarding the equipment and the procedure of the study. During the procedure, the subjects inhaled deeply and then exhaled with maximum effort as much as possible in to the mouth piece. The following parameters were recorded: Forced vital capacity (FVC), Forced expiratory volume in the first second( $\left.\mathrm{FEV}_{1}\right)$, Forced expiratory volume percent $\left(\mathrm{FEV}_{1} / \mathrm{FVC} \%\right)$, Peak expiratory flow rate(PEFR), Forced expiratory flow 25$75 \%\left(\mathrm{FEF}_{25-75 \%}\right)$ and Maximum voluntary ventilation(MVV).

\section{Results}

The data were expressed as mean \pm SD. The data was analyzed by Students ' $t$ ' test. The $p$ values less than 0.05 was considered significant. The heights of females were found to be less than males "TABLE" 1. In diabetic subjects, there was significant decrease in FVC ( $<<0.001), \mathrm{FEV}_{1}(\mathrm{p}<0.001), \mathrm{FEV}_{1} / \mathrm{FVC} \%$ $(\mathrm{p}<0.01)$, PEFR $(\mathrm{p}<0.001), \mathrm{FEF}_{25-75 \%}(\mathrm{p}<0.001)$ and MVV $(\mathrm{p}<0.001)$ compared to non-diabetic subjects "TABLE" 2. In female diabetic subjects, there was significant reduction in FVC $(p<0.001), \mathrm{FEV}_{1}(\mathrm{p}<0.001)$, PEFR $(\mathrm{p}<0.001), \mathrm{FEF}_{25-75 \%}(\mathrm{p}<0.01)$ and MVV $(\mathrm{p}<0.001)$ compared to male diabetic subjects "TABLE" 3.

Table 1: General parameters in male and female subjects. 


\begin{tabular}{|l|l|l|l|l|}
\hline \multirow{2}{*}{$\begin{array}{l}\text { General } \\
\text { parameters }\end{array}$} & \multicolumn{2}{|c|}{ Male } & \multicolumn{2}{c|}{ Female } \\
\cline { 2 - 5 } & $\begin{array}{l}\text { Diabetics } \\
(\mathbf{n = 3 0})\end{array}$ & $\begin{array}{l}\text { Non-Diabetics } \\
(\mathbf{n = 3 0})\end{array}$ & $\begin{array}{l}\text { Diabetics } \\
(\mathbf{n = 2 0})\end{array}$ & $\begin{array}{l}\text { Non-Diabetics } \\
(\mathbf{n}=\mathbf{2 0})\end{array}$ \\
\hline Age $(\mathrm{Yrs})$ & $48.87 \pm 8.91$ & $41.27 \pm 8.04$ & $48.05 \pm 7.97$ & $45.75 \pm 8.21$ \\
\hline Weight $(\mathrm{Kg})$ & $62.33 \pm 9.07$ & $62.37 \pm 7.99$ & $65.1 \pm 10.70$ & $60.9 \pm 5.93$ \\
\hline Height $(\mathrm{Cm})$ & $162.1 \pm 5.87$ & $162.13 \pm 6.49$ & $153.3 \pm 3.74$ & $154.3 \pm 3.29$ \\
\hline BSA $(\mathrm{sq} \mathrm{m})$ & $1.66 \pm 0.14$ & $1.66 \pm 0.13$ & $1.63 \pm 0.12$ & $1.62 \pm 0.12$ \\
\hline BMI $\left(\mathrm{Kg} / \mathrm{m}^{2}\right)$ & $23.66 \pm 2.66$ & $23.72 \pm 2.33$ & $27.68 \pm 4.12$ & $25.80 \pm 2.49$ \\
\hline
\end{tabular}

Data are mean \pm SD age and Anthropometric values are not statistically significant $(\mathrm{P}>0.05)$

Table 2: PFT parameters in male and female subjects.

\begin{tabular}{|l|l|l|l|l|}
\hline \multirow{2}{*}{ PFT Parameters } & \multicolumn{2}{|c|}{ Male } & \multicolumn{2}{c|}{ Female } \\
\cline { 2 - 5 } & $\begin{array}{l}\text { Diabetics } \\
(\mathbf{n = 3 0})\end{array}$ & $\begin{array}{l}\text { Non-Diabetics } \\
(\mathbf{n = 3 0})\end{array}$ & $\begin{array}{l}\text { Diabetics } \\
(\mathbf{n = 2 0})\end{array}$ & $\begin{array}{l}\text { Non-Diabetics } \\
(\mathbf{n}=\mathbf{2 0})\end{array}$ \\
\hline $\mathrm{FVC}(\mathrm{L})$ & $2.04 \pm 0.40$ & $3.16 \pm 0.37^{*}$ & $1.36 \pm 0.30$ & $2.11 \pm 0.25^{*}$ \\
\hline $\mathrm{FEV}_{1}(\mathrm{~L})$ & $1.65 \pm 0.49$ & $2.86 \pm 0.36^{*}$ & $1.12 \pm 0.34$ & $1.88 \pm 0.25^{*}$ \\
\hline $\mathrm{FEV}_{1} / \mathrm{FVC} \%$ & $81.67 \pm 16.80$ & $90.59 \pm 6.08^{* *}$ & $81.56 \pm 12.55$ & $89.63 \pm 10.01^{* * *}$ \\
\hline $\mathrm{PEFR}^{(\mathrm{L} / \mathrm{S})}$ & $3.35 \pm 1.05$ & $5.97 \pm 0.78^{*}$ & $2.43 \pm 0.81$ & $4.24 \pm 0.55^{*}$ \\
\hline $\mathrm{FEF}_{25-75 \%}(\mathrm{~L} / \mathrm{S})$ & $1.92 \pm 0.87$ & $3.36 \pm 0.69^{*}$ & $1.26 \pm 0.57$ & $2.62 \pm 0.35^{*}$ \\
\hline $\mathrm{MVV}(\mathrm{L})$ & $77.51 \pm 20.60$ & $112.28 \pm 21.88^{*}$ & $42.82 \pm 16.38$ & $68.01 \pm 7.19^{*}$ \\
\hline
\end{tabular}

Data are mean $\pm \mathrm{SD} ; * \mathrm{P}<0.001, * * \mathrm{P}<0.01, * * * \mathrm{p}<0.05$

Table 3: Comparison of PFT parameters among Male \& Female subjects.

\begin{tabular}{|l|l|l|l|l|}
\hline \multirow{2}{*}{ PFT Parameters } & \multicolumn{2}{|c|}{ Diabetics } & \multicolumn{2}{c|}{ Non-diabetics } \\
\cline { 2 - 5 } & Male $(\mathbf{n}=\mathbf{3 0})$ & Female $(\mathbf{n = 2 0})$ & Male $(\mathbf{n = 3 0})$ & Female $(\mathbf{n = 2 0})$ \\
\hline $\mathrm{FVC}(\mathrm{L})$ & 2.036 & $1.356^{*}$ & 3.157 & $2.107^{*}$ \\
\hline $\mathrm{FEV}_{1}(\mathrm{~L})$ & 1.652 & $1.1195^{*}$ & 2.856 & $1.879^{*}$ \\
\hline $\mathrm{FEV}_{1} / \mathrm{FVC} \%$ & 81.67 & 81.57 & 90.58 & 89.62 \\
\hline $\mathrm{PEFR}^{(\mathrm{L} / \mathrm{S})}$ & 3.348 & $2.429^{*}$ & 5.970 & $4.239^{*}$ \\
\hline $\mathrm{FEF}_{25-75 \%}(\mathrm{~L} / \mathrm{S})$ & 1.923 & $1.26^{* *}$ & 3.359 & $2.62^{* *}$ \\
\hline $\mathrm{MVV}(\mathrm{L})$ & 77.50 & $42.82^{*}$ & 112.27 & $68.01^{*}$ \\
\hline
\end{tabular}

Data are mean value; * Mark indicates comparison with males. $* \mathrm{P}<0.001$, $* * \mathrm{P}<0.01$.

\section{Discussion}

Recent studies conducted by Lange et al. and Asanuma et al indicate that both IDDM and NIDDM patients are associated with slight reduction in FVC and it was because of impaired defense against environmental challenges such as smoking and airway infections in diabetes [8,9]. There was increased cross-linkage formation between polypeptides of collagen in pulmonary connective tissue, which decreases FVC and hence is responsible for restrictive respiratory defects. There was significant reduction in mean FVC in all diabetic patients and the reduction was more pronounced in female diabetics than male diabetics. $\mathrm{FEV}_{1}$ is the volume of air that is exhaled in the first second during FVC manoeuvre. It is useful to detect generalized airway obstruction. The Mean $\mathrm{FEV}_{1}$ values showed significant reduction in male as well as female diabetics. These findings were consistent with findings of Meo et al. and Davis et al [6]. $\mathrm{FEV}_{1} / \mathrm{FVC}^{\circ}$ is the volume of air expired in the first second, expressed as percentage of FVC. It is a more sensitive indicator of airway obstruction, than $\mathrm{FVC}$ or $\mathrm{FEV}_{1}$ alone. The alteration in collagen and elastin ratio is the main factor in the diabetic patients. The decrease in $\mathrm{FEV}_{1} / \mathrm{FVC} \%$ in diabetic subjects may be related with the poor mechanical properties of the lung, like lung compliance and elastic recoil of lungs. Loss of elastic recoil leads to dynamic collapse of small airways during expiration. In addition, myopathic or neuropathic changes affecting the respiratory muscles further impairs the endurance, efficiency of ventilatory pump. A study conducted by Ali Mo et al. showed similar findings but was not significant [1]. Sreeja et al. reported almost similar type of finding [10].

$\mathrm{FEF}_{25-75 \%}$ is the average flow rate during middle $50 \%$ of FVC. It indicates patency of the small airways. FEF $25-75 \%$ depends on non-bronchopulmonary factors like, neuromuscular factors and mechanical 
equipment factors of inertial distortion of lungs. The thickening of alveolar wall due to the increased amounts of collagen and elastin in basal lamina results in microangiopathy. There was a significant reduction in FEF $25-75 \%$ among diabetics compared to controls, shows a lower airway caliber and higher airway resistance and this finding was similar to Ashapherwani et al and Malcom Sandler et al [11]. MVV is the maximum breathing capacity which is decreased in poor respiratory muscle strength, emphysema etc. There was a significant reduction in MVV values in both male and female diabetics compared to controls, shows poor skeletal muscle strength due to increased protein catabolism. A study conducted by Park SW et al. and Meo SA et al. showed similar results. The mean values of pulmonary function parameters were significantly decreased in female diabetics compared to male diabetics. The less height of females might have contributed to this decrease as respiratory functions are affected by height of individual.

We summarize that the diabetic subjects show a greater decrease in PFT values compared to nondiabetic subjects. Also, the PFT values are decreased in female diabetics compared to male diabetics.

\subsection{Pulmonary complications in Diabetes}

The Diabetic patients are susceptible to a series of complications, which include: Microvascular complications like diabetic retinopathy, diabetic nephropathy and diabetic neuropathy, which appear with in $5-10$ years of duration of diabetes. Macrovascular complications like coronary artery disease, peripheral vascular disease develop usually $15-20$ years from the onset of diabetes [12,13]. Defective pulmonary function is also seen in diabetes [12]. The pulmonary complications in asymptomatic diabetic patients is more prevalent than generally recognized. The lungs are affected by diabetic microangiopathy. This is evidenced by autopsy findings in human diabetic subjects which show thickening of alveolar epithelia, pulmonary capillary basal lamina, centrilobular emphysema, and pulmonary microangiopathy [12] .

\subsubsection{Lung Mechanical abnormalities in diabetes}

Tests related to lung mechanical function include lung elasticity, airflow resistance, and maximal forced spirometric pulmonary function tests (PFTs).The potential mechanisms of decreased lung function is explained by non-enzymatic glycosylation of proteins, such as collagen in the lungs and chest wall. This glycosylation leads to irreversible collagen cross-linking, rendering to decreased proteolysis and accumulation of collagen in lung connective tissue [13]. The glycosylation process occurs in the early stages of diabetes, when hyperglycemia is most pronounced until new equilibrium is reached at lower turnover rate of collagen. Chronic hyperglycemia causes fibrous tissue formation in the chest wall and bronchial tree protein by non-enzymatic glycation. This may cause reduced compliance of lung and chronic airflow obstruction [14]. Diabetes mellitus is also associated with poor skeletal muscle strength due to increased protein catabolism. Thus, respiratory muscle endurance decreases in diabetes mellitus.

\subsubsection{Gas exchange in diabetes}

The diffusing capacity for carbon monoxide is reduced in diabetes. This may be due to loss of surface area and membrane thickening.

\subsubsection{Diabetes, autonomic neuropathy, and respiratory function}

The patients with diabetes complicated by autonomic neuropathy have impaired control of bronchomotor tone. Resting vagal tone is depressed which explains the depressed bronchoconstrictory response to both cholinergic stimuli and hyperventilation with cold air [13]. Thus, there is a complex alteration of both control of ventilation and bronchomotor tone in diabetic patients with automatic neuropathy.

\subsubsection{Diabetes induced oxidative stress and the lung}

Hyperglycemia causes over production of mitochordrial superoxides and reduction in anti-oxidant defence of the lungs [14]. The glycation of proteins can lead to oxidative stress by direct release of $\mathrm{O}_{2}$ and $\mathrm{H}_{2} \mathrm{O}_{2}$, and activation of phagocytes through a specialized receptor for advanced glycosylation end products (AGEs). Oxidants include reactive oxygen species (ROS), reactive nitrogen species (RNS), sulphur centered radicals and others. Phagocytic cells generate large amounts of NO and ROS. In diabetes there are alterations in antioxidant enzymes, impaired glutathione metabolism, and decreased ascorbic acid levels. Nitric oxide is produced by nitric oxide synthase (NOS). Three different forms of NOS expressed in lungs are neuronal (n NOS), endothelial (e NOS), and inducible (i NOS). Excessive NO produced by i NOS and 
its potent oxidative derivative peroxynitrate via oxidation, hydroxylation, and nitration is involved in acute lung injury [14].

The alvelolar capillary network is the largest microvascular organ (Surface area $140 \mathrm{~m}^{2}$ ) and receives entire cardiac output [15]. As the pulmonary reserves are larger, the symptoms and disability from diabetes develop earlier in other organs than in the lungs.

\section{Conclusion}

We conclude that diabetic subjects show a decrease in PFT values compared to non-diabetic subjects. Also, female diabetics are more prone to respiratory dysfunction than male diabetics. The findings of present study suggest that, lung is a target organ for damage in diabetes and the glycemic exposure is a strong determinant of reduced pulmonary function in type 2 diabetics. As measures of airflow limitation predict all-cause mortality in type 2 diabetes, intensive glycemic management may reduce the risk of death through improved ventilatory function independent of other beneficial effects. As pulmonary dysfunction may be one of the earliest and easily measurable non-metabolic alteration in diabetes, the patients with diabetes are suggested to undergo pulmonary function testing along with other investigations.

\section{References}

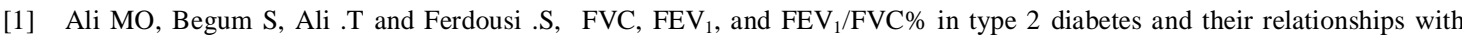
duration of the disease, J. Bangladesh Soc Physiol.,4(2), 2009 Dec, 81- 87.

[2] WHO Diabetes programme, 2011 Jan, Fact sheet no. 312.

[3] Sarah Wild et al., Global prevalence of diabetes, Diabetes Care, 27(5), 2005 May : 1047 - 1053.

[4] Wiliam F. Ganong, Endocrine function of pancreas and regulation of carbohydrate metabolisms, Review of Medical Physiology, 22 ${ }^{\text {nd }}$ edition, (India: Mc Graw-Hil Company, 2003) Ch 19:340 - 354, 649.

[5] Sandler M, Is the lung a "target organ" in diabetes mellitus? Arch int Med., Vol. 150,1990 July, 1385 - 1388.

[6] Davis et al., Glycemic exposure is associated with reduced pulmonary function in type 2 diabetes, The Fremantle diabetes study, Diabetes Care, 27 (3), 2004 March, 752 - 757.

[7] Spirown version 2.0., The Pulmonary function test system, User Manual, (Hyderabad :Genesis Medical Systems Pvt. Ltd, 2006).

[8] Sreeja C.K, Elizabeth Samuel, C. Kesavachandran and Shankar Shashidhar, Pulmonary function in patients with Diabetes Mellitus, IJPP, 47 (1), $2003,87-93$.

[9] P. Lange, J. Parner, P. Schnohr and G. Jensen, Copenhagen city heart study : longitudinal analysis of ventilatory capacity in diabetic and non-diabetic adults, Eur Rspir J, 20, 2002, 1406 -1412.

[10] G. Engstrom and L. Janzon, Risk of developing diabetes is inversely related to lung function : a population - based cohort study, Diabetic Medicine, 19,2002, 167 - 170.

[11] M. Sandler, A.E. Bunn and R.I. Stewart, Pulmonary function in young insulin-dependent diabetic subjects, Chest, 90,1986 , $670-675$.

[12] A. Kaparianos, E. Argyropoulou and F. Sampsonas, Pulmonary complications in diabetes mellitus, Chronic respiratory disease, 5 , 2008, $101-108$.

[13] Engelgau. M.M. \& Geiss L.S, The burden of diabetes mellitus, Leahy .T.L, Clark .N.G., Cefalu W.T, Medical Management of diabetes mellitus (New York: Marcel Dekker ,2000).

[14] The diabetes control and complications trial research group, The effect of intensive treatment of diabetes on the development and progression of long-term complications in insulin-dependent diabetes mellitus, N Eng J Med, 329,1993, 977 - 986.

[15] Mason, Murray and Nadel's, Text book of Respiratory Medicine, $4^{\text {th }}$ edition,( Saunders : Elsevier Publications, 2005). 